\title{
Analysis on Electric Vehicles Solving Carbon Emission Problem
}

\author{
Shuyang $\mathrm{He}^{*}$ \\ Montgomery High School, Skillman, The United States, 08558
}

\begin{abstract}
The purpose of this paper is to give a general idea about the future of electric vehicles (EV) and their effects on carbon emission. More specifically, an analysis of the complete transition to EVs by 2050 and whether renewable energy would be enough to supply their electricity demand. Some difficulties are facing such a transition and its background. To support the analysis, an estimation of the supply and demand of electricity in the United States is made using assumptions and data provided by (mostly) government agencies. The estimation uses existing data to predict the amount of renewable power available for EVs in 2050 and the amount of power that EVs will require. These predictions have pointed out that power generated by renewable means (by 2050) available for EVs and the EVs' power needs are both around 1 trillion $\mathrm{kWh}$. Further discussions about energy storage and transportation conclude that the power generated by renewable energy may not be able to cover all the energy needs of EVs but a significant amount. The complete transition to EV in the future will largely be supported by clean and renewable energy, so the transition is warranted as it will greatly reduce carbon emissions, pollution, and even global warming.
\end{abstract}

\section{Introduction}

Global warming is a major, worldwide problem today that endangers the well-being of humans and other species. To reduce global warming, the greenhouse effect and carbon emission, the viability of traditional cars is called into question. Gasoline vehicles and combustion engines emit a large amount of carbon dioxide into the atmosphere, contributing to the greenhouse effect. Replacements for these cars and especially electric cars are viewed as a solution to this problem. By transitioning away from gasoline vehicles, governments seek to achieve zero-emission in passenger cars. Recent policies in the United States limiting the sale of gasoline vehicles put forth the question of whether the nation is ready for a future transition to EV. In order to analyze the problem, many factors need to be considered and worked through before a conclusion can be reached. One of the most important factors is that there must be enough renewable energy to supply EVs with clean, carbon-free, electricity. A transition to EV that runs on fossil fuel-generated electricity is not helpful for environment. But even if human beings can manage to generate enough clean energy for the new $\mathrm{EVs}$, the transition from conventional fossil fuel cars to EVs would not be easy. In addition to driving electric cars, Americans will also need to build more renewable energy facilities and infrastructure.

\section{Carbon mission and global warming}

With the fast growth and expansion of industrial production worldwide in the past few decades, environmental pollution has become increasingly serious. These problems will threaten the quality of life of people as well as sustainable economic development. Among many challenges, greenhouse gasses and global warming is big concern. Despite the great effort people have made to control carbon emission since the 1980 s, we see in Figure 1 that the emission has increased steadily.

Today's human-caused greenhouse gas emissions are higher than ever. The major contributors to greenhouse gases are factories, heating, and automobiles. Large amounts of gases emitted by industries and cars (carbon dioxide) form a layer over the atmosphere, making it impossible for Earth's heat to dissipate effectively, which leads to global warming. Between pre-industrial times and now, the Earth's average temperature has increased by 1.8 degrees Fahrenheit. With such high temperatures, many problems can occur, such as melting ice caps, species going extinct, and more severe weather or natural disasters. These are all problems that can negatively affect human beings worldwide.

Reducing the emission of greenhouse gases, especially that of $\mathrm{CO} 2$, is the consensus of the international community and an essential way to deal with global warming. A series of conventions and meetings were held among global leaders and many agreements, such as the Paris Climate Agreement with certain mandatory objectives, have been signed. The international agreement assures the success of emission reduction, as no single country alone can solve this problem.

\footnotetext{
* Corresponding author: shuyang.he@mtsdstudent.us
} 


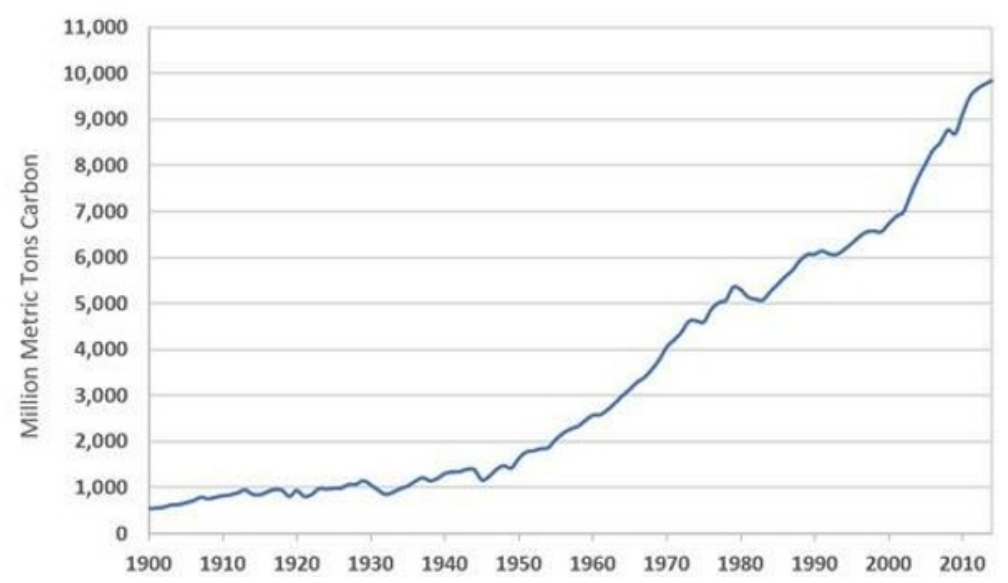

Figure 1. Global carbon emissions from fossil fuels (1900-2014) [2]

\section{Electric Vehicles and Clean Energy}

In an attempt to lower their emissions, 15 countries have decided to make a transition from gasoline vehicles to electric ones. Joining this effort is governor Newsome of California, who recently announced an executive order that will end the sale of gasoline cars by 2035 . Other states in the nation are expected to follow his lead and make their own commitments to zero-emission vehicles. Although this trend seems to help the environment, it is necessary to dive deeper into the issue and determine whether a national transition to electric cars (or electric vehicles, EV) will likely achieve the intended goal. The U.S. has one of the largest amounts of cars in the world, with totals of 270 million [1]. Transportation is also the largest source of pollution in the United States. To solve the climate crisis, the U.S. needs to make vehicles on the roads as clean as possible. Governments worldwide have only a decade left to change the way people use energy and avoid the worst impacts of climate change.

Because of this, Electric cars have been growing rapidly over the past ten years with the global stock of electric passenger cars passing 5 million in 2018 and a $63 \%$ increase from the previous year. Around $45 \%$ of electric cars on the road in 2018 were in China - a total of 2.3 million - compared to $39 \%$ in 2017 . In contrast, Europe accounted for $24 \%$ of the global fleet, and the United States 22\%. (source: IEA research)

To better understand car emissions, the carbon emission of EVs' whole life cycle needs to be looked at. Production of electricity by burning fossil fuel to power EVs can also produce a large amount of carbon dioxide. Two of the most common fossil fuels used today to generate electricity are natural gas and coal. Burning coal releases upwards of 200 pounds of carbon dioxide (the exact number depends on the type of coal) per million British thermal units of energy produced. Burning natural gas releases 117 pounds of carbon dioxide for the same amount of energy [3]. Therefore, the method of producing electricity is another vital component of lower carbon emission. While burning fossil fuel worsens the environment, using renewable energy does not. However, it is important to note that some studies have suggested even if an EV is fully charged with the electricity produced with thermal power using coal and natural gas, it is still cleaner than gas-powered cars. Once the vehicles get on the road, it's a whole different energy story due to better efficiency enabled by advanced technology.

There are many discussions about EVs being 25-50\% more efficient than conventional cars. However, unlike traditional cars, EVs can be powered without fossil fuels entirely. Given that the batteries of an electric car are charged using the local power grid, electric cars are as clean as that grid. In theory, if the local power supply were drawn from a mix of hydro, wind, solar, and nuclear power, operating electric cars would have zero emissions. When powered by renewable energy, like solar and wind, driving EV is virtually emission-free. The electric car is cleaner in every way when compared to a conventional, gasoline-burning car, even when they are charged with electricity generated by fossil-fuel burning plants.

\section{Method}

To achieve the goal of zero-emission, all EVs should be charged with electricity or energy storage products powered by clean and renewable energy. It is, thus, important to know whether the increased demand for energy created by EVs could be sufficiently met by renewables sources. This paper will attempt to answer this question using secondary data analysis.

Currently, there are only around 2 million EVs in the U.S. However, future growth will be accelerated. If the growth of EVs is dynamic as many it seems, we need to analyze and determine if the foundation is there to support the growth. Let us start with the upstream of EV, the electricity generation. Assuming all states of America decide to follow California's example and ban the sale of gasoline cars by 2035 since our goal is zerofree emission, we need to figure out whether renewable energy will be enough to satisfy the needs of EVs based on the assumptions of the following:

(A) A car has a life of more than 10 years, so, in this scenario, by 2050 when the last conventional gas- 
powered car is out of the market, all cars on the road should be electric [4].

(B) Car parc in 2050 is at least 270 million (assuming no growth) [1]

(C) The average car owner drives 13,476 miles per year [5]

(D) The average electric car can travel 100 miles using 30 kilowatt-hours of electricity [6]. Therefore, in 2050 that all the cars are electric, the amount of electricity required to power all these cars be calculated by the following formula:

$(270 \mathrm{million}) *(13,476 \mathrm{mi} / \mathrm{yr}) *(30 / 100 \mathrm{kWh} / \mathrm{mi})$

$=$ Approximately 1.1 trillion $\mathrm{kWh}$.

billion kilowatthours

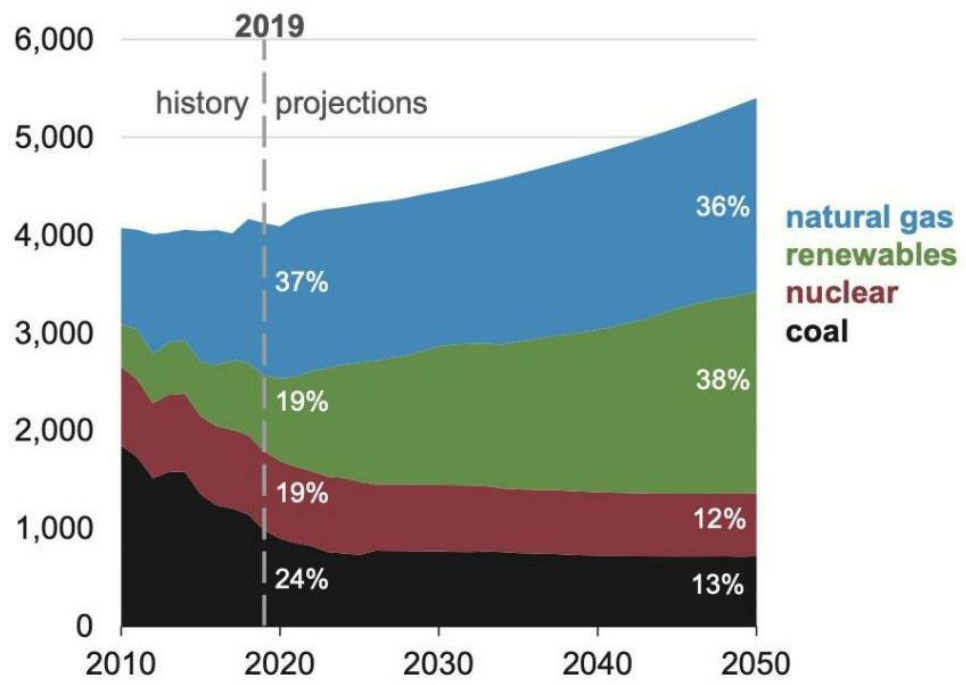

Figure 2. Electricity generation from selected fuels [7]

\section{Results}

A successful EV transition can be defined as a 100percent substitution of fossil fuels by renewable energy by 2050 , which would result in zero-emission. The amount of electricity needed for EVs in 2050 is approximately 1.1 trillion $\mathrm{kWh}$. This number is very similar to the amount of renewable electricity available for cars, also at around 1 trillion $\mathrm{kWh}$. Although there is a 0.1 trillion $\mathrm{kWh}$ difference, due to the nature of this analysis, it may not be significant. For the energy transition to succeed, the renewable share of electric power for EV use would have to increase to $100 \%$, which is in fact projected to occur. Thus, the results of the analysis suggest that a complete transition to EVs would allow us to greatly reduce greenhouse gas generation that is accelerating climate change. However, that being said, several issues may reduce the amount of renewable electricity available for EVs. They are mainly consisted of energy storage and electricity losses during transmission.

\section{Discussion}

Currently, the US Energy Information Administration predicts that in 2050, renewable energy will take up $38 \%$ of the total national electricity production. In 2019, that number was 19\%. Most EVs today are not charged with renewable energy and most of that electricity is being used in other areas [7]. Assuming all increases in renewable energy, which is $19 \%$ from 2019 to 2050, were used to power the cars and not for other purposes and the national electricity production is 5500 billion $\mathrm{kWh}$ [7], then the renewable electricity available for cars comes down to 1.0 trillion $\mathrm{kWh}(0.19$ * 5500 billion). Thus, the amount of renewable electricity available and the electricity needed to operate all the cars in America is very similar (both at around 1 trillion $\mathrm{kWh}$ ). 
towns and cities, requiring the construction of new transmission lines. Some energy will be lost here as electricity transmission and distribution is not a hundred percent efficient and loses about 5\% of energy [8].

Since the supply of renewable energy and demand for EV electricity is so similar (both around 1 trillion $\mathrm{kWh}$ ), these additional issues may cause the demand for electricity to slightly surpass the supply. However, these losses are unlikely to grow exceedingly great and with adequate planning in areas like energy storage, use, and transportation, the renewable energy generated should be able to cover most (though not all) EV demands. Therefore, a transition to EVs is warranted even though not $100 \%$ of its electricity will come from renewable sources because enough zero-emission EVs will be running on clean and renewable energy to make a significant contribution. To realize a future running on clean EVs, more wind and solar farms and transmission lines will have to be built, but it is not inconceivable that these developments would be in place by 2050 .

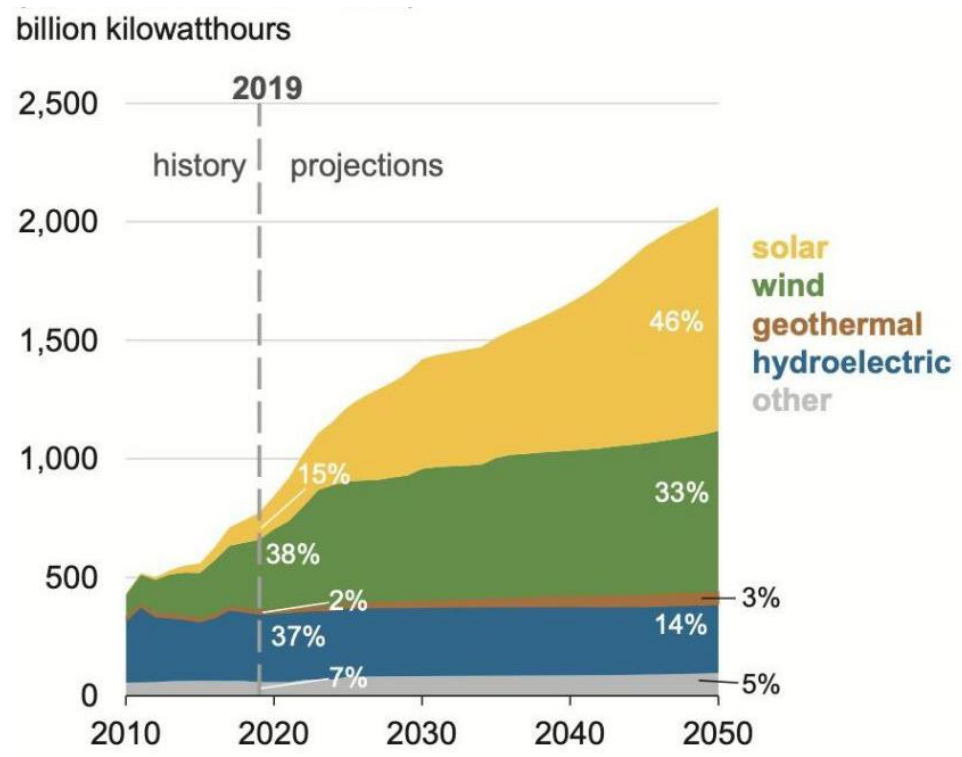

Figure 3. Renewable electricity generation including end use[7]

To achieve the objective of significantly lowering emissions by 2050 , we are still facing many challenges. The above estimations use EIA trends of renewable energy developments, but whether the United States will be able to follow that trend is another issue. The EIA predicts that by $2050,38 \%$ of the U.S.' energy would come from renewable, but it is not as easy as one might think.

The requirements for space and resources are concerns. Renewable potential typically demands huge land use as compared with fossil fuels. The various types of renewable energy typically require much more materials such as metal as fossil fuels to produce the same amount of energy.

Also, we are used to having electricity on demand. And since it can't be stored, it also has to be consumed when it is produced. Wind and solar energy, which are available when the sun shines and the wind blows, don't meet these two conflicting demands. Further storage developments are required. The persistent effort needs to be made to strengthen and speed up the transition process.

\section{Conclusion}

Based on the above discussion, it seems clear that renewable energies will not be able to completely replace fossil fuels for EV power needs in a foreseeable future. The transition could be significant yet partial. That being said, there are still concerns about renewable energy's availability for application and consumption in any place and any time. To minimize carbon emission and satisfy the energy demand for EVs, some comprehensive plans to design and build optimal energy structures that could efficiently utilize both renewable energy and fossil fuel need to be laid out and executed. The focus should be on technological improvements, and perhaps even further development into new energy sources.

In order to solve the problem of the difficulty to store and transmit the electricity generated by renewable sources, more advanced technologies may, again, prove to be of great help. Similar applications, such as energy reserve technology, rechargeable, and replaceable batteries may also be beneficial. As we mentioned at the beginning of this discussion, with the government's plan, support is an essential part of the effort, either through commercial subsidies or mandatory guidance, the market would respond to facilitate the development of EVs and the use of renewable energy. Overall effects of these transitions would benefit the environment and help reduce carbon emissions.

I wish to thank professor Budimir Rosic for spurring my interest in energy and environmental science, and his guidance in my writing of this paper. I also want to thank Ms. Sun for 
reviewing my research and presentation. Their support has been inspirational and crucial.

\section{REFERENCES}

1. Bureau of Transportation Statistics. "Number of U.S. Aircraft, Vehicles, Vessels, and Other Conveyances." bts.gov, BUREAU OF TRANSPORTATION

STATISTICS.www.bts.gov/content/number-usaircraft-vehicles-vessels-and-other-conveyances.

2. U.S. Energy Information Administration. "How Much Carbon Dioxide Is Produced

3. When Different Fuels Are Burned?" eia.gov, U.S. Energy Information Administration, www.eia.gov/tools/faqs/faq.php?id=73\&t=11.

4. BUREAU OF TRANSPORTATION STATISTICS. "Average Age of Automobiles and Trucks in Operation in the United States." bts.gov, BUREAU OF TRANSPORTATION STATISTICS. www.bts.gov/content/average-age-automobiles-andtrucks-operation-united-states.

5. Federal Highway Administration. "Average Annual Miles per Driver by Age Group." fhwa.dot.gov,
Federal Highway Administration, www.fhwa.dot.gov/ohim/onh00/bar8.htm.

6. Fueleconomy.gov. National Laboratory for the U.S. Department of Energy and the U.S. Environmental Protection Agency. www.fueleconomy.gov/feg/PowerSearch.do?action =noform\&path=1\&year $1=2017 \&$ year $2=2019 \&$ vtyp $\mathrm{e}=$ Electric \&pageno3\&sortBy $=$ Comb \&tabView $=0 \& \mathrm{r}$ owLimit $=10$.

7. U.S. Energy Information Administration. "ANNUAL ENERGY OUTLOOK 2020." eia.gov, U.S. Energy Information Administration, www.eia.gov/outlooks/aeo/.

8. The United States Environmental Protection Agency. "Global Greenhouse Gas Emissions Data." epa.gov, United States Environmental Protection Agency. www.epa.gov/ ghgemissions/global-greenhousegas-emissions-data.

9. U.S. Energy Information Administration. "How much electricity is lost in electricity transmission and distribution in the United States?" eia.gov, U.S. Energy Information Administration. www.eia.gov/tools/faqs/faq.php?id=105\&t=3. 